\title{
Malignant peripheral nerve sheath tumours in inherited disease
}

\author{
D Gareth R Evans ${ }^{1,3^{*}}$, Susan M Huson ${ }^{1}$ and Jillian M Birch ${ }^{2}$
}

\begin{abstract}
Background: Malignant peripheral nerve sheath tumours (MPNST) are rare tumours known to occur at high frequency in neurofibromatosis 1 (NF1), but may also occur in other cancer prone syndromes.

Methods: The North West Regional Genetic Register covers a population of 4.1 million and was interrogated for incidence of MPNST in 12 cancer prone syndromes. Age, incidence and survival curves were generated for NF1.

Results: Fifty two of 1254 NF1 patients developed MPNST, with MPNST also occurring in 2/181 cases of schwannomatosis and 2/895 NF2 patients. Three cases were also noted in TP53 mutation carriers. However, there were no cases amongst 5727BRCA1/2 carriers and first degree relatives, 2029 members from Lynch syndrome families, nor amongst 447 Familial Adenomatous Polyposis, 202 Gorlin syndrome, nor 87 vHL cases.

Conclusion: MPNST is associated with schwannomatosis and TP53 mutations and is confirmed at high frequency in NF1. It appears to be only increased in NF2 amongst those that have been irradiated. The lifetime risk of MPNST in NF1 is between 9-13\%.
\end{abstract}

Keywords: Sarcoma, MPNST, NF1, Li Fraumeni, TP53, SMARCB1, NF2

\section{Introduction}

Malignant peripheral nerve sheath tumour (MPNST) are uncommon tumours varying substantially in clinicopathologic features [1]. Previous studies have shown that $20 \%-50 \%$ of patients with MPNST also have Neurofibromatosis type 1 (NF1) [2-4]. Cutaneous MPNST is very rare [5-7]; skin involvement is usually secondary to local invasion or metastasis from larger underlying tumours. Most are high grade, poorly differentiated and aneuploid. Only half can be shown to exhibit schwannian differentiation by immunohistochemical methods. Tumours exhibiting mesenchymal primarily rhabdomyosarcomatous differentiation (Triton tumour) are often associated with NF1 [8]. The lifetime risk of MPNST in NF1 has previously been assessed as between $8-13 \%$ [4]. However, there has been limited evidence of association with other tumour prone disorders, with only case

\footnotetext{
*Correspondence: gareth.evans@cmft.nhs.uk

${ }^{1}$ Genetic Medicine, The University of Manchester, Manchester Academic Health Science Centre, Central Manchester Foundation Trust, St. Mary's Hospital, Oxford Road, Manchester M13 9WL, UK

${ }^{3}$ Manchester Academic Health Science Centre, Genetic Medicine, St Mary's Hospital, Central Manchester Hospitals Foundation Trust, Manchester M13 9WL, UK

Full list of author information is available at the end of the article
}

reports showing associations with TP53 mutations [9] and schwannomatosis[10]. We have reviewed our genetic register databases for presence of MPNST amongst affected cases and for non-syndromic conditions their first degree relatives (FDRs). The conditions studied are summarised in Table 1.

\section{Methods}

The North West Regional Genetic Register covers a region of North West England, based around Manchester, with a population of 4.1 million. The genetic register service covers a number of tumour predisposing syndromes in particular NF1, Neurofibromatosis type 2 (NF2), Familial Adenomatous Polyposis (FAP), Gorlin syndrome, von Hippel Lindau disease and non-syndromic families with BRCA1, BRCA2, MSH2, MLH1 and MSH6 mutations. The register is highly ascertained for NF1, NF2, FAP, Gorlin syndrome von Hippel Lindau disease [11]. In addition there is a regional database of TP53 mutation carriers and an international database for schwannomatosis patients referred into the Manchester laboratory for SMARCB1 mutation analysis. All the registries have been the subject of cancer verification using the regional

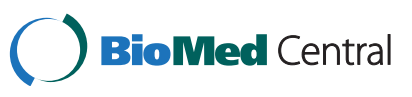


Table 1 Diagnostic criteria for NF1 (two or more must be present)

\begin{tabular}{llll}
\hline Disease & Birth incidence & Main tumour associations & Known risk of MPNST \\
\hline NF1 & 1 in 2,712 & Neurofibroma, MPNST, gliomaAML, phaeochromocytoma & yes \\
\hline Schwannomatosis & 1 in 100,000 & Schwannoma, meningioma & No \\
\hline NF2 & 1 in 33,000 & Schwannoma, meningioma, ependymoma & Only after irradiation \\
\hline BRCA1 & 1 in 900 & Breast cancer, Ovarian cancer & No \\
\hline BRCA2 & 1 in 850 & Breast cancer, Ovarian cancer, prostate cancer & No \\
\hline TP53 & 1 in 3000 & Breast cancer, sarcoma, glioma, lung cancer, adreno-cortical & possible \\
\hline FAP & 1 in 8,619 & Colorectal, duodenal, hepatoblastoma, thyroid & No \\
\hline MSH2 & 1 in 2000 & Colorectal, endometrium, ovarian, upper urothelial, gastric, glioma & No \\
\hline MLH1 & 1 in 2000 & Colorectal, endometrium, ovarian, upper urothelial, gastric, glioma & No \\
\hline MSH6 & 1 in 10,000 & Colorectal, endometrium, ovarian, upper urothelial, gastric, glioma & No \\
\hline vHL & 1 in 42,987 & Renal cancer, haemangioblastoma & No \\
\hline Gorlin syndrome & 1 in 18,976 & Basal cell carcinoma, medulloblastoma & No
\end{tabular}

North West Cancer Intelligence Service (NWCIS). We have previously published risks of cancers in Lynch syndrome [12] and cancer incidence in BRCA1 and BRCA2 carriers [13]. The NWCIS ascertains patients with malignancies of all sites, as well as benign central nervous system tumours, from pathology records and death certificates. We previously reviewed the Cancer Register for patients with MPNST (ICD-0: M9540/3 and 9560/3) from 1984-1996 [4]. We reviewed hospital notes for all patients with MPNST who were identified for the study. To corroborate a diagnosis of NF1, histology reports and details of other typical NF1 disease features were reviewed (e.g., café-au-lait macules and neurofibromas with respect to the U.S. National Institutes of Health diagnostic criteria[11]). As a diagnosis is straightforward in most cases of NF1, NF2, vHL, Gorlin syndrome and FAP only affected cases were used in the analysis. As previously we also used all FDRs of known mutation carriers for Lynch syndrome (MSH2, MLH1, MSH6) [12] and $B R C A 1 / 2$ [14] as $50 \%$ of these are likely to carry the pathogenic mutation.

Death details from the registries were used to calculate survival rates, and death certificates were reviewed to determine cause of death. Follow-up was censored on $1^{\text {st }}$ April 2010. MPNST incidence curves were derived for NF1 for strict regional residents to avoid ascertainment bias. Five-year survival was determined using Kaplan-Meier curves. NF1 MPNST cases who were identified on the periphery of the region during the study period were included for the survival analysis only. The Mann-Whitney $U$ test and Wilcoxon (Gehan) statistic were used to test between-group differences in age at diagnosis and survival.

\section{Results}

The presence of MPNST among the study populations is shown in Table 2. There were no instances of MPNST amongst 5727 BRCA1/2 carriers and first degree relatives, nor among 2029 Mismatch Repair mutation carriers and first degree relatives from Lynch syndrome families. As the annual rate of MPNST is about 1.25 per million [4] the lifetime risk in the general population would be about 1 in 10,000. There could be some confidence therefore that MPNST does not occur at increased incidence in BRCA1/2 carriers but not yet in Lynch syndrome. There were also no cases amongst vHL, Gorlin or FAP patients although numbers were smaller. The presence of two male cases with MPNST aged 32 (retro-orbital) and 33 years (lower limb) and one female case of triton tumour aged 5 years amongst carriers of a $524 \mathrm{G}>\mathrm{A}$ (Arg175His), a 574delC and a 375 G > A TP53 mutation respectively suggests a likely association with Li Fraumeni syndrome. The $375 \mathrm{G}>\mathrm{A}$ mutation affects the invariant splice donor site CG/g > $\mathrm{CA} / \mathrm{g}$ in exon 4. The missense and splicing mutation were inherited, but the framshift deletion de novo. There were also a further three benign nerve sheath tumours in three further unrelated TP53 mutation carriers aged 33 years (Vestibular schwannoma) and two paraspinal/ extra-dural at ages 50 and 49 years. There were also three cases with schwannomatosis and MPNST. Two of these occurred in a family with a c.846 C > G, p.N288K SMARCB1 mutation that we have previously reported as probably pathogenic [15]. It appears this Australian family has been reported as part of a hospital series, but they were not noted to have a SMARCB1 mutation [10]. Both had high grade MPNSTs with one now metastatic aged 27 years and the other having died aged 17 years. A third case in an individual with multiple spinal (5) schwannomas and a peripheral schwannoma occurred aged 46 from which he died. SMARCB1 mutation analysis was not possible. There were two cases occurring amongst 921 NF2 patients. Both of these have been reported as having occurred after radiation treatment 
Table 2 Incidence of MPNST in 12 tumour prone genetic conditions

\begin{tabular}{llllll}
\hline Disease & Cases at risk & MPNST & MPNST after radiation treatment & Sex ratioM:F & Median (range) age at diagnosis \\
\hline NF1 & 1252 & 52 & 4 & $22: 30$ & $31(13.3-77.2)$ \\
\hline Schwannomatosis & 181 & 3 & 0 & $2: 1$ & $26(17-45)$ \\
\hline NF2 & 920 & 2 & 2 & $1: 1$ & $25-34$ \\
\hline BRCA1 & $2992^{*}$ & 0 & 0 & & $2: 1$ \\
\hline BRCA2 & $2735^{*}$ & 0 & 0 & & $32(1-33)$ \\
\hline TP53 & $221^{*}$ & 3 & 0 & & \\
\hline FAP & 477 & 0 & 0 & & \\
\hline MSH2 & $1054^{*}$ & 0 & 0 & & \\
\hline MLH1 & $897^{*}$ & 0 & 0 & & \\
\hline MSH6 & $178^{*}$ & 0 & 0 & & \\
\hline VHL & 87 & 0 & 0 & & \\
\hline Gorlin syndrome & 202 & 0 & 0 & & \\
\hline
\end{tabular}

${ }^{*}$ Cases include first degree relatives of known mutation carriers.

for vestibular schwannoma [16,17]. No MPNSTs occurred in unirradiated NF2 patients.

There were 52 cases of MPNST amongst our NF1 patients including 43/1059 patients within the strict regional.boundaries of the Cancer Register. Fifteen cases of MPNST have occurred in the strict regional population since 1996 maintaining an incidence rate of above 1 per 1000 NF1 patient per year as 1010 NF1 patients were alive at some point after 1996.

\section{NF1 MPNST lifetime risk}

Within the strict regional population of 1059 individuals the cumulative risk of MPNST was $11.7 \%$ (95\% CI 9.7$13.7 \%$ ) by age 70 years (figure 1). The robustness of incidence beyond 70 years is influenced by a single case in a

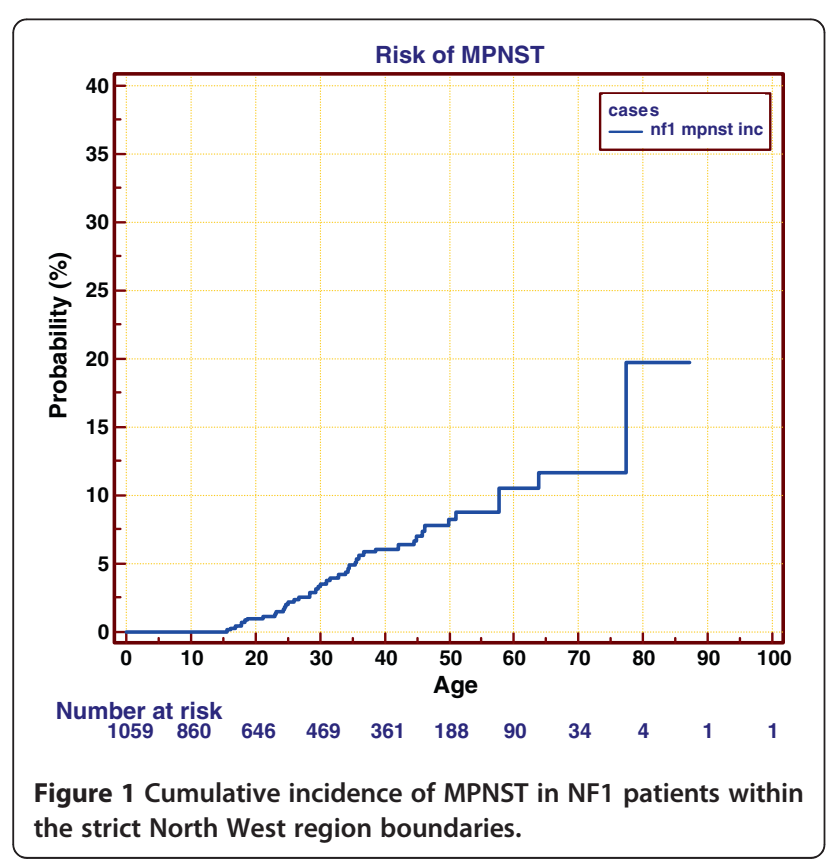

female aged 77 years in a population with only 34 patients living beyond 70 years.

\section{Discussion}

The association between MPNST and NF1 has long been documented [2-4,18-22]. The present report doubles the size of our previous report of MPNST in NF1 [4] and provides further confirmation for the lifetime risk estimates. As only cases with MPNST within the strict highly ascertained borders of the region are included these remain robust. There have been fifteen MPNSTs in our regional population in the fourteen years since our last population based study [4]. The annual incidence of above 1 per 1000 NF1 patients has been maintained over now a 27-year period. The lifetime risk of MPNST in NF1 is estimated at $11.7 \%$ with tighter confidence intervals than previously. Survival remains poor in NF1 with only one third of patients alive at 5 years post diagnosis. This is in accordance with our previous publication [4]. Although we have also recently reported an improved survival in recent years (since 1996) and significantly better survival in females versus males (5-year survival $46 \%$ vs $22 \%$ ) with NF1 [23]. MPNST remains the single biggest contributing factor to reduced life expectancy in NF1 $[16,18,24]$.

In addition to the known link with NF1 this study has confirmed probable links with schwannomatosis and germline TP53 mutations. The presence of three proven MPNSTs in only 181 schwannomatosis patients is very suggestive of an association. The main difficulty with this association is the previous problems with classifying schwannomatosis [25-27]. However, the presence of two MPNSTs in a family with a proven SMARCB1 mutation suggests that this is a real link. It also broadens the tumour spectrum in families with $S M A R C B 1$ mutations. There remains a question as to why children with certain SMARCB1 mutations have a very high risk of the 
highly Malignant atypical teratoid Rhabdoid tumours [28] whereas other families appear to get only schwannomas [15] although meningiomas also occur at a variable frequency $[15,29,30]$.

The presence of three confirmed TP53 mutation carriers with MPNST makes a link with germline TP53 mutations and Li Fraumeni syndrome very likely. It is quite possible that cases of MPNST are buried amongst reports of soft tissue sarcoma [31]. It is therefore likely that occult/unrecognized LFS patients/families could come to light from performing TP53 analysis on MPNST patients. Both the cases of MPNST occurred after the previous report from our group [31]. Nonetheless the only clear report of a TP53 mutation was a case of Triton tumour in a three year old [9]. This report also suggests that this was the first such case in the literature whereas the further triton tumour case in our series was evident from our previous report [31].

The link between NF2 and MPNST is controversial $[16,17,32-35]$. There have been a number of reports of MPNST following radiation therapy $[16,17,33]$ in NF2, but only two reports of apparently spontaneous MPNST without radiotherapy [34,36]. The first report is, nonetheless, questionable as it describes multifocal MPNST in addition to neurofibromata, which would be more consistent with NF1 than NF2. The second describes a patient with a unilateral vestibular schwannoma that developed contralateral cranial MPNST[36] as such neither report refers to a patient with proven NF2. The first report[34] also describes the possibility of a constitutional TP53 mutation, which in addition to an NF1 mutation may cause a very substantial risk of MPNST. Indeed TP53 mutations have been described in the transformation from benign schwannoma to MPNST [32]. Although the risk of MPNST appears to be higher in TP53 mutation carriers this will need to be confirmed in larger studies.

Up to $50 \%$ of malignant peripheral nerve sheath tumours in non NF1 patients harbour NF1 mutations [37]. There is a broad spectrum of NF1 mutations in MPNST and in the germline of those NF1 patients that develop MPNST [38,39]. Although the risk of MPNST appears to be substantially higher in individuals with large deletions removing the NF1 gene [40], these patients still only make up a small proportion of all cases of MPNST in NF1 $[38,39]$. A better test needs to be derived to target a high risk population in NF1 for screening. It is possible that assessing whole body tumour burden and particularly the extent of large deep seated tumours at age 15-20 years may detect a sub-population at enhanced risk [41]. Whilst MRI can detect volumetric changes that may presage malignant change, Positron Emission Tomography (PET) is the most sensitive and specific test to determine if a tumour has become malignant $[42,43]$.
Nonetheless the significant dose of radiation involved in PET means this should not be used in routine screening in a cancer prone syndrome [16]. Detection of a subset at risk by genetic analysis and whole body MRI followed by regular MRI of suspicious lesions for increased volumetric growth alongside greater patient awareness may improve survival from the current poor levels in NF1.

The poor survival from MPNST particularly in NF1 patients highlights the need for therapies targeted at the main underlying genetic abnormality. Whole genome sequencing is likely to reveal new targets for therapy and the fast reducing cost of such testing may mean that it will be affordable in the clinic within the next 5 years.

In conclusion MPNST appears to occur at increased frequency in schwannomatosis and in those with germline TP53 mutations as well as those with NF1. Radiation treatment particularly in childhood increases the risk of MPNST in NF1 and may also cause MPNST to occur in NF2.

\section{Competing interests}

The authors declare that they have no competing interests.

\section{Authors' contributions}

The research and reviews conceived by DGE, initial manuscript and data assessed by DGE, contributions for data on TP53 from JMB and from SMH for NF1. All authors developed the manuscript and approved the final version.

\section{Acknowledgements}

We acknowledge the National Specialist Commissioning team for their support of the National Complex NF1 service and the NF2 service. The department of Genetic Medicine in Manchester is supported by the NIHR Manchester Biomedical Research Centre.

\section{Author details}

${ }^{1}$ Genetic Medicine, The University of Manchester, Manchester Academic Health Science Centre, Central Manchester Foundation Trust, St. Mary's Hospital, Oxford Road, Manchester M13 9WL, UK. ${ }^{2}$ Cancer Research UK Paediatric and Familial Cancer Research Group, University of Manchester, Room 1.900 Stopford Building, Oxford Road, Manchester M13 9PT, UK. ${ }^{3}$ Manchester Academic Health Science Centre, Genetic Medicine, St Mary's Hospital, Central Manchester Hospitals Foundation Trust, Manchester M13 9WL, UK.

Received: 4 November 2011 Accepted: 14 March 2012 Published: 4 October 2012

\section{References}

1. Scheithauer BW, Woodruff JM, Erlandson RA. Primary malignant tumors of peripheral nerve. In Tumors of the Peripheral Nervous System. Atlas of Tumor Pathol; Armed Forces Institute of Pathology 1999: pp.303-72.

2. Sorensen SA, Mulvihill JJ, Nielsen A: Long term follow up of von Recklinghausen neurofibromatosis: survival and malignant neoplasms. N Engl J Med 1986, 314:1010-1015.

3. D'Agostino AN, Soule EH, Miller RH: Primary malignant neoplasms of nerves (malignant neurolemmomas) in patients without multiple neurofibromatosis (Von Recklinghausen disease). Cancer 1963, 16:1003-1014

4. Evans DGR, Baser ME, McGaughran J, Sharif S, Donnelly B, Moran A: Malignant peripheral nerve sheath tumours in neurofibromatosis 1. J Med Genet 2002, 39:311-314.

5. George E, Swanson PE, Wick MR: Malignant peripheral nerve sheath tumors of the skin. Am J Dermatopathol 1989, 11:213-221.

6. Misago N, Ishii $Y$, Kohda H: Malignant peropheral nerve sheath tumor of the skin: a superficial form of this tumor. J Cutan Pathol 1996, 23:182-188. 
7. Hirose T, Scheithauer BW, Sano T: Malignant perineurioma. A study of 7 cases. Am J Surg Pathol 1998, 22:1368-1378.

8. Woodruff JM, Perino G: Non-germ cell or teratomatous malignant tumors showing additional rhabdomyoblastic differentiation, with emphasis on the malignant "Triton" tumor. Demin Diagn Surg Pathol 1994, II:69-81.

9. Chao MM, Levine JE, Ruiz RE, Kohlmann WK, Bower MA, Petty EM, Mody RJ: Malignant triton tumor in a patient with Li-Fraumeni syndrome and a novel TP53 mutation. Pediatr Blood Cancer 2007, 49(7):1000-1004.

10. Gonzalvo A, Fowler A, Cook RJ, Little NS, Wheeler H, McDonald KL, Biggs MT: Schwannomatosis, sporadic schwannomatosis, and familial schwannomatosis: a surgical series with long-term follow-up. J Neurosurg 2011, 114(3):756-762.

11. Evans DG, Howard E, Giblin C, Clancy T, Spencer H, Huson SM, Lalloo F: Birth incidence and prevalence of tumour prone syndromes: estimates from a UK genetic family register service. Am J Med Genet 2010, 152A(2):327-332.

12. Barrow E, Robinson L, Aldhuaj W, Shenton S, Lalloo F, Hill J, Evans DG: Extracolonic cancers in HNPCC: Cumulative lifetime incidence and tumour distribution. A report of 121 families. Clin Genet 2009, 75(2):141-149.

13. Moran A, O'Hara C, Khan S, Shack L, Woodward E, Maher ER, Lalloo F, Evans DG. Risk of cancer other than breast or ovarian in individuals with BRCA1 and BRCA2 mutations. Fam Cancer. 2011 Dec 21. [Epub ahead of print]

14. Evans DG, Shenton A, Woodward E, Lalloo F, Howell A, Maher ER: Penetrance estimates for BRCA1 and BRCA2 based on genetic testing in a Clinical Cancer Genetics service setting. BMC Cancer 2008, 8(1):155.

15. Hadfield KD, Newman WG, Bowers NL, Wallace A, Bolger C, Colley A, McCann E, Trump D, Prescott T, Evans DGR: Molecular characterisation of SMARCB1 and NF2 in familial and sporadic schwannomatosis. J Med Genet 2008, 45(6):332-339.

16. Evans DGR, Birch JM, Ramsden RT, Moffat D, Baser ME: Malignant transformation and new primary tumours after therapeutic radiation for benign disease: substantial risks in certain tumour-prone syndromes. J Med Genet 2006, 43(4):289-294.

17. Bari ME, Forster DM, Kemeny AA, Walton L, Hardy D, Anderson JR: Malignancy in a vestibular schwannoma. Report of a case with central neurofibromatosis, treated by both stereotactic radiosurgery and surgical excision, with a review of the literature. Br J Neurosurg 2002, 16:284-289

18. Poyhonen M, Niemela S, Herva R: Risk of malignancy and death due to neurofibromatosis. Arch Pathol Lab 1997, 121:139-143.

19. Rasmussen SA, Yang Q, Friedman JM: Mortality in neurofibromatosis 1:an analysis using US death certificates. Am J Hum Genet 2001, 68:1110-1118.

20. Ducatman B, Scheithauer B, Piepgras D, Reiman H, Istrup D: Malignant peripheral nerve sheath tumors: a clinicopathological study of 120 patients. Cancer 1986, 57:2006-2021.

21. Wanebo J, Malik J, VandenBerg S, Wanebo H, Driessen N, Persing J: Malignant peripheral nerve sheath tumors: a clinicopathological study of 28 cases. Cancer 1993, 71:1247-1253.

22. Doorn P, Molenar W, Buter J, Hockstra H: Malignant peripheral nerve sheath tumors in patients with and without neurofibromatosis. Eur J Surg Oncol 1995, 21:78-82.

23. Ingham S, Huson SM, Moran A, Wylie J, Leahy M, Evans DG: Malignant peripheral nerve sheath tumours in NF1: Improved survival in women and in recent years. Eur J Cancer 2011, 47(18):2723-2728.

24. Evans DG, Howard E, Moran A, Ingham S, Scott-Kitching V, Holt F, Huson SM. Mortality in neurofibromatosis 1. Eur J Hum Genetics 2011; in press.

25. MacCollin M, Chiocca EA, Evans DG, Friedman JM, Horvitz R, Jaramillo D, Lev M, Mautner VF, Niimura M, Plotkin SR, Sang CN, Stemmer-Rachamimov A: Roach ES Diagnostic criteria for schwannomatosis. Neurology 2005, 64(11):1838-1845.

26. Murray A, Hughes TAT, Neal JW, Howard E, Evans DGR, Harper PS: A case of multiple cutaneous schwannomas; schwannomatosis or neurofibromatosis type 2? J Neurol Neurosurg Psychiat 2006, 77(2):269-271.

27. Baser ME, Friedman JM, Evans DG: Increasing the specificity of diagnostic criteria for schwannomatosis. Neurology 2006, 66(5):730-732.

28. Bourdeaut F, Lequin D, Brugières L, Reynaud S, Dufour C, Doz F, André N, Stephan JL, Pérel Y, Oberlin O, Orbach D, Bergeron C, Rialland X Fréneaux P, Ranchere D, Figarella-Branger D, Audry G, Puget S, Evans DG, Pinas JC, Capra V, Mosseri V, Coupier I, Gauthier-Villars M, Pierron G,
Delattre O: Frequent hSNF5/INI1 Germline Mutations in Patients with Rhabdoid Tumor. Clin Cancer Res 2011, 17(1):31-38.

29. Bacci C, Sestini R, Provenzano A, Paganini I, Mancini I, Porfirio B, Vivarelli R, Genuardi M, Papi L: Schwannomatosis associated with multiple meningiomas due to a familial SMARCB1 mutation. Neurogenetics 2010, 11(1):73-80.

30. Christiaans I, Kenter SB, Brink HC, van Os TA, Baas F, van den Munckhof $P$, Kidd AM, Hulsebos TJ. Germline SMARCB1 mutation and somatic NF2 mutations in familial multiple meningiomas. J Med Genet. 2010 Oct 7 [Epub ahead of print] Hadfield KD, Smith MJ, Trump D, Newman WG, Evans DG.SMARCB1 mutations are not a common cause of multiple meningiomas. J Med Genet. 2010;47(8):567-8.

31. Birch JM, Alston AD, McNally RJQ, Evans DGR, Kelsey AM, Harris M, Eden OB, Varley JM: Relative frequency and morphology of cancers in 28 Li-Fraumeni families with germline TP53 mutations. Oncogene 2001, 20:4621-4628.

32. Shin $M$, Ueki $K$, Kurita $H$, Kirino $T$ : Malignant transformation of a vestibular schwannoma after gamma knife radiosurgery. Lancet 2002, 360:309-310.

33. Balasubramaniam A, Shannon P, Hodaie M, Laperriere N, Michaels $H$, Guha A: Glioblastoma multiforme after stereotactic radiotherapy for acoustic neuroma: Case report and review of the literature. Neuro Oncol 2007, 9(4):447-453.

34. Higami Y, Shimokawa I, Kishikawa M, Okimoto T, Ohtani H, Tomita M, Tsujino A, Ikeda T: Malignant peripheral nerve sheath tumors developing multifocally in the central nervous system in a patient with neurofibromatosis type 2. Clin Neuropathol 1998, 17(2):115-120.

35. Scheithauer BW, Erdogan S, Rodriguez FJ, Burger PC, Woodruff JM, Kros JM, Gokden M, Spinner RJ: Malignant peripheral nerve sheath tumors of cranial nerves and intracranial contents: a clinicopathologic study of 17 cases. Am J Surg Pathol 2009, 33(3):325-338.

36. Ziadi A, Saliba I: Malignant peripheral nerve sheath tumor of intracranial nerve: a case series review. Auris Nasus Larynx 2010, 37(5):539-545.

37. Bottillo I, Ahlquist T, Brekke H, Danielsen SA, van den Berg E, Mertens F, Lothe RA, Dallapiccola B: Germline and somatic NF1 mutations in sporadic and NF1-associated malignant peripheral nerve sheath tumours. J Pathol 2009, 217(5):693-701.

38. Upadhyaya M, Kluwe L, Spurlock G, Mantripragada K, Monem B, Majounie E, Chuzanova N, Evans DG, Ferner R, Thomas N, Guha A, Mautner V: The germline and somatic NF1 gene mutation spectrum in NF1-associated malignant peripheral nerve sheath tumours (MPNSTs). Hum Mutation 2008, 29(1):74-82.

39. Upadhyaya M, Spurlock G, Majounie E, Griffiths S, Forrester N, Baser M, Huson SM, Gareth Evans D, Ferner R: The heterogeneous nature of germline mutations in NF1 patients with malignant peripheral serve sheath tumours (MPNSTs). Hum Mutat 2006, 27(7):716.

40. De Raedt T, Brems H, Wolkenstein P, Vidaud D, Pilotti S, Perrone F, Mautner V, Frahm S, Sciot R, Legius E: Elevated risk for MPNST in NF1 microdeletion patients. Am J Hum Genet 2003 May, 72(5):1288-1292.

41. Mautner VF, Asuagbor FA, Dombi E, Fünsterer C, Kluwe L, Wenzel R, Widemann BC, Friedman JM: Assessment of benign tumor burden by whole-body MRI in patients with neurofibromatosis 1. Neuro Oncol 2008 , 10(4):593-598.

42. Ferner RE, Lucas JD, O'Doherty MJ, et al: Evaluation of (18) fluorodeoxyglucose positron emission tomography (FDG PET) in the detection of malignant peripheral nerve sheath tumours arising from within plexiform tumours in neurofibromatosis 1. J Neurol Neurosurg Psychiat 2000, 68:353-357.

43. Ferner RE, Golding JF, Smith M, Calonje E, Jan W, Sanjayanathan V, O'Doherty M: [18F]2-fluoro-2-deoxy-D-glucose positron emission tomography (FDG PET) as a diagnostic tool for neurofibromatosis 1 (NF1) associated malignant peripheral nerve sheath tumours (MPNSTs): a long-term clinical study. Ann Oncol 2008, 19(2):390-394.

doi:10.1186/2045-3329-2-17

Cite this article as: Evans et al:: Malignant peripheral nerve sheath tumours in inherited disease. Clinical Sarcoma Research 2012 2:17. 